This is a pre-copyedited, author-produced version of an article accepted for publication in The Monist following peer review. The version of record Nick Zangwill, The Yummy and the Yucky: Expressive Language and the Agreeable, The Monist, Volume 101, Issue 3, July 2018, Pages 294-308 is available online at: https://doi.org/10.1093/monist/ony007.

\title{
The Yummy and the Yucky: Expressive Language and The Agreeable
}

\section{Nick Zangwill??}

When tasting food or drink, we may exclaim: “Yummy!” or “Yucky!” or “Delicious!” or "Disgusting!”. What do these words mean? What do we mean when we use these words? And what are we doing when we use these words? In the neighborhood of these questions about language are questions about judgements of the agreeable. This is something Kant addresses in his Critique of Judgement (Kant 1928). But in this paper, I want to keep the focus on the language of the agreeable. It might be objected that we should direct our attention to thought, and language is only relevant as an imperfect guide to thought. Nevertheless, I hope to show that there is something distinctive about expressive language, which makes it interesting in its own right.

Different parts of human language do different things. The idea I shall explore is that some of what we say does not aim to represent the world, but is expressive of non-cognitive mental states, such as feelings of pleasure or displeasure - not merely in the sense that the language can be used to be expressive of such states of mind, but in the sense that it is the dedicated function of these words to be expressive of such states of mind. In this paper, I make some remarks on the expressive language of the agreeable in the hope of understanding its basic nature and structure.

I begin with some framing remarks about referential and literal language before giving a positive account of the expressive language of the agreeable. Once that is in place, logical properties of expressive language can be addressed.

There is much to say about food and drink besides discussing the expressive language that we use to talk about it. Nevertheless, this language, I believe, has a certain centrality. Food and drink may have personal or cultural significance, and they may have political symbolism and the like. But in order to play these roles, they must have flavor, they must have a taste, which we may describe with expressive language. Food and drink do many things, but without their taste and flavor and the pleasure we take in these, it would not do the other things that it does.

\section{§1. Meaning/Reference}

How is the primary function of words fixed? We might be interested in language in general, or in certain portions of language. In my view, the right approach to the general theory of 
This is a pre-copyedited, author-produced version of an article accepted for publication in The Monist following peer review. The version of record Nick Zangwill, The Yummy and the Yucky: Expressive Language and the Agreeable, The Monist, Volume 101, Issue 3, July 2018, Pages 294-308 is available online at: https://doi.org/10.1093/monist/ony007.

language is to understand it in terms of evolutionary game theory, which delivers a plausible general account of linguistic meaning. (I doubt that it has any real competitors.) On this account, linguistic conventions are set up by dynamic feedback processes that generate convergence on certain symbol-world mappings rather than others. These constitute linguistic conventions. Thus "dog" means dog because that symbol-world correlation has evolved (culturally), in the sense of being selected by negative feedback mechanisms, and which is dynamically stable in a certain community, within certain limits of perturbations. It is stable because divergences from the mapping are costly and continuing the mapping has benefits. (For two examples of an extensive genre see Nowak and Krakauer 1999; Nowak, Plotkin and Krakauer 1999.) Remark: game-theory here is not a theory of rational decision, but a model of complex interacting entities, subject to multiple feedback loops, which applies both to biological evolution (Maynard Smith 1982), as well as to cultural evolution (Lewens 2013). We are not utilizing game-theory in the sense of prisoner's dilemmas, this is rather game-theory in the sense in which host-parasite ratios may be predicted.

Such a view of language, as a culturally evolved institution, is, in broad outlines, the account originally suggested by Ludwig Wittgenstein, under the influence of the economist Sraffa (as Engleman 2011/2013 has emphasized), and then articulated formally, but in a flawed way, by David Lewis in his book Convention (Lewis 1969). The main flaw was in the overintellectualist attribution of 'common knowledge', which is (a) not necessary, and (b) intuitively and psychologically implausible (Aumann and Brandenburger 1995, Binmore 2009). But this flaw can be subtracted leaving the program in tact. The program has been taken up by game-theorists interested in dynamic evolutionary processes since that time. (This idea is more influential outside philosophy than inside it; Ruth Millikan 2005 and Brian Skyrms 2010 are prominent philosophers who have pursued it.) On this account of linguistic meaning, when we 'go on' in the application of a word to a new case, we have no reasons (we do so 'blindly') but it is nevertheless no accident that we get it right (Wittgenstein 1953, section 219). We participate in the stable linguistic institution and there is a game-theoretic explanation of that, but participants need not know that explanation. They just have to be trained in a practice, that is evolutionarily stable. They have linguistic knowledge, which is primarily practical knowledge, without reasons.

At the center of such a theory are symbol-world correlations. Such language is fundamentally referential. In standard cases, the function of a name is to pick out an object or event, and the 
This is a pre-copyedited, author-produced version of an article accepted for publication in The Monist following peer review. The version of record Nick Zangwill, The Yummy and the Yucky: Expressive Language and the Agreeable, The Monist, Volume 101, Issue 3, July 2018, Pages 294-308 is available online at: https://doi.org/10.1093/monist/ony007.

function of a predicate is to pick out a property. (The latter claim is non-Fregean; they do not typically function to pick out concepts.) Linguistic items thus turn out to be functional things (like tools) whose essence is defined in part by their history. The history of how a word acquires its word-world mapping is not distant and irrelevant history, but a history that defines what the word is for, and, as with all functional things, what it is for defines what it is.

In order to get language up and running, there need to be dynamic feedback mechanisms encouraging convergence on certain symbol-world associations. This is referred to as 'signaling' because by means of the symbol one player can signal a particular thing or property to the receiver of the signal. This, when a certain stability is achieved, is what it is for the word "Napoleon" to mean the man Napoleon, and for the word "yellow" to mean the color yellow. Evolutionary language-game-theory describes the mathematical mechanisms whereby these linguistic institutions come into existence in complex dynamic situations with multiple players. This is the basic idea of evolutionary language-game-theory.

Given such linguistic meanings, we may have linguistic intentions and linguistic beliefs. But one of the main advantages of evolutionary language-game-theory is that these intentions and beliefs are not fundamental or necessary in the way that Paul Grice and his followers thought (Grice 1957). Indeed, evolutionary language-game-theory explains what Grice assumes. If we have beliefs and intentions with semantic contents, there needs to be something that is linguistic meaning that these thoughts are about. This is necessary if we are to intend or believe something with semantic content. Evolutionary language-game-theory gives us that.

\section{§2. Belief/Non-belief; Literal/Non-literal}

To say that signaling language has the dedicated function of being referential is not at all, not remotely, not in the slightest, not even a tiny bit, the same thing as saying that the language conveys beliefs. Reference is one thing; belief is another. Sentences that refer to something may or may not stand in some systematic relation to beliefs about that thing. Language that conveys beliefs has no special status compared to language that conveys other intentional states. We could speak a language that only conveyed our desires and hopes, and we could speak a language only of jokes or only of questions. There is no reason to connect linguistic reference especially to the propositional attitude of belief. What is important is that the words refer.

Another crucial point is this. Nothing in evolutionary language-game-theory means that we always use referential language to refer to what it is supposed to refer to. Donald Davidson's 
This is a pre-copyedited, author-produced version of an article accepted for publication in The Monist following peer review. The version of record Nick Zangwill, The Yummy and the Yucky: Expressive Language and the Agreeable, The Monist, Volume 101, Issue 3, July 2018, Pages 294-308 is available online at: https://doi.org/10.1093/monist/ony007.

theory of metaphor beautifully builds on literal linguistic meaning to describe a use of literal words with literal meanings (Davidson 1978). It is a very large misunderstanding of Davidson's view of metaphor to interpret it as somehow fundamentally 'non-cognitive'. The uses of literal language that metaphor involves might derive from cognitive states or from non-cognitive states. It is crucial to understand metaphor correctly, otherwise the attempt to describe expressive language will misfire — the waters between the two being muddied. The two phenomena need to be separated. By a wall.

Something with a dedicated function, such as a coffee-maker, need not always be used in accordance with its function. We may use a coffee maker to make coffee or as a paper-weight. There is artifact-abuse (Capra 2014). It is similar with linguistic functions. A word's meaning is its function, which can be used and abused, like using a coffee-maker either to make coffee or as a paper-weight. One can use a functional thing, such as a coffee-maker or a word, either in accordance with its function, and one can also use it in a way that has nothing to do with its function. But the meaning of words remains the same in uses that accord with their function and in uses that diverge from their function. Indeed, as Davidson emphasized, metaphorical uses depends on literal word meaning remaining unchanged. Metaphor is a form of deliberate meaning abuse that depends on literal meaning (Zangwill 2014). A word may have the dedicated function of signifying a certain object or property, but not be used to do so. Its meaning is its function, but its use may be another matter. Metaphor does not signal a departure from referential language; it depends on it. That referential meaning is what is deliberately misused, or abused.

\section{§3. Expressive Meaning}

In any particular area of language, there will be specific features that need a specific evolutionary game theoretic explanation and interpretation. Thus far, material object referential language has been the main pursuit of the evolutionary language-game-theory program. Logic and predication have not been much explored. Neither has expressive language for the agreeable — which is what I explore here, in the light of the above framework. In particular, I explore the language of the agreeable as applied to food and drink

I shall pursue the idea that our language contains words with dedicated non-referential functions. (At the risk of repeating myself and being really really boring: 
This is a pre-copyedited, author-produced version of an article accepted for publication in The Monist following peer review. The version of record Nick Zangwill, The Yummy and the Yucky: Expressive Language and the Agreeable, The Monist, Volume 101, Issue 3, July 2018, Pages 294-308 is available online at: https://doi.org/10.1093/monist/ony007.

referential=/=cognitive; non-referential=/=non-cognitive; and referential meaning=/=referential use.)

Let us use the word "aesthetic" to indicate matters of beauty and ugliness. (This is not Kant's usage.) Whether aesthetic talk is expressive is highly controversial and should not be assumed. (Isidora Stojanovic (Stojanovic 2007), Timothy Sundall (Sundall 2011) and other quasiempirical recent writers on aesthetic language make this assumption without argument or evidence.) I wish to remain neutral on this question here. Hence my focus is on the language of the agreeable, not the beautiful. Talk of the agreeable is obviously and uncontroversially expressive. I put to one side the large question of whether aesthetic language is expressive, and examine uncontroversially expressive language, and in particular on the agreeable in food and drink —on what is 'delicious' or 'disgusting', or, more childishly, what is 'yummy' and 'yucky' to taste (in the primary literal sense of 'taste').

There are agreeable things besides food and drink. A cool breeze on a hot day may be agreeable, as may be a hot shower on a cold day. And many aspects of works of art are classifiable in terms of the agreeable rather than other art-valuable categories, such as beauty or profundity. Works of art are complex, with many features and functions and different works of art have different features and functions. The aesthetic may feature in various ways in different works of art. Moreover, as Carolyn Kormeyer has emphasized, food and drink are also complex with various functions besides how they taste (Korsmeyer 2002). Food or drink may be nutritious or intoxicating, for example. There may be religious or personal family functions of food. And the visual presentation of food may be beautiful. Food and drink may have functions as complex as many works of art; it is not only for eating and drinking (Kass 1994).

Nevertheless, they often please us by their flavour - the way they taste. And this is where the expressive language of the agreeable comes in.

Not all pleasures in food and drink are pleasure in eating and drinking it. And again, not all pleasures in eating and drinking are pleasures in the flavor of the food or drink. The trouble with some very fat people is not that they enjoy tasting food and drink too much, but the very opposite. They do not enjoy tasting food and drink enough! They may enjoy the physical actions of eating or drinking, but this is more a pleasure in feeling the bulk of the food or drink descending in the throat or stomach (as Aristotle said $<$ reference to follow?? $>$ ). It is matter of touch not taste. This is not pleasure in the taste of food or drink. If they enjoyed food more in this way, they would eat and drink less of it! 
This is a pre-copyedited, author-produced version of an article accepted for publication in The Monist following peer review. The version of record Nick Zangwill, The Yummy and the Yucky: Expressive Language and the Agreeable, The Monist, Volume 101, Issue 3, July 2018, Pages 294-308 is available online at: https://doi.org/10.1093/monist/ony007.

"Yummy" and "Yucky" are non-referential language that we use in response to tasting food and drink. Such expressive discourse is very different from response-dependent or relational or subjectivist language, according to which such language represents relations to psychological facts. This would be referential talk. (Undergraduates are trained to grasp the expressivist/subjectivist distinction. But I am not sure that recent 'contextualist' or 'relativist' ideas about the language of taste do not confuse these two ideas. See, for example, McFarlane 2014.)

I take it that Kant is right that the predicate "agreeable" contrasts with the aesthetic predicate "beautiful" since there is an idea of correctness in play in judgments of beauty that is not there in judgments of deliciousness (Kant 1928; for defense of Kant on this point see Zangwill 2018). Those who do not enjoy smoked salmon are not wrong not to like it or to say that it is 'disgusting' or 'yucky'. However, the fact that I like it makes it appropriate, in normal circumstances, for me to say that it is "delicious" or "yummy". That is a rule for assertion in accordance with its function. (I return to this rule below.)

To say that there is no norm of correctness in judgements of the agreeable is not to say that we cannot mistakenly apply the assertion rule. If I have recently eaten blue cheese, then orange juice will taste odd, and vice versa. These are not circumstances in which to employ the rule of assertion, since the pleasure or displeasure should be taken in the food or drink in optimal circumstances. But that does not amount to a norm of correctness like the one we have for judgements of beauty, whereby the judgement that proceeds from pleasure or displeasure tacitly claims that the opposite judgement is less appropriate than it. (I explore this norm of correctness further in Zangwill 2018). Needless to say, or I think it should be needless to say, that the notion of 'truth' should not be brought in to illuminate any of these matters. Truth only makes a mess. We do far better to proceed with the idea of correctness.

In a sophisticated early paper, Charles Stevenson described the 'dynamic' use of words and he distinguishes that from emotive meaning (Stevenson 1937). By 'dynamic' he meant what could be achieved by the use of language, which today we would call 'pragmatics'. This distinction is important. The idea of emotive meaning, as Stevenson intends it, is not the idea of a 'pragmatic' use of words, which is a matter of what the words can be used to achieve or cause. That would be a confusion. A pragmatic theory would in fact lose the distinctive idea of emotive meaning. A pragmatic theory would be nearly as problematic as contextual or relativist 
This is a pre-copyedited, author-produced version of an article accepted for publication in The Monist following peer review. The version of record Nick Zangwill, The Yummy and the Yucky: Expressive Language and the Agreeable, The Monist, Volume 101, Issue 3, July 2018, Pages 294-308 is available online at: https://doi.org/10.1093/monist/ony007.

theories. This is not the way to think of the expressive or emotive language of the agreeable. What is the right way, then? $<<$ Check this?? $>>$

\section{§4. Expressive Predication}

We need an account of expressive predication. In fact, we need a far better grip on the notion of 'expression' than what has been presented thus far, in a somewhat casual way. To do this, we need to construct a serviceable notion of expression, rather than rely on anything intuitive or historically given.

Consider a handshake. What exactly does a handshake mean? It does mean something. And what it means is something different from a high-five. You don't do a high-five when you meet the Queen of the United Kingdom. Another example would be Sraffa’s famous rude Italian gesture, which led Wittgenstein to abandon his picture theory of meaning. It certainly means something-'something offensive. What do these gestures mean though, if there is no reference, no symbol-world institutions that constitutes their meaning? Well, so long as the right kind of dynamic feedback mechanism is in place, the institution, the hand-shake, can come into existence. Even if we, who practice this rite, cannot quite say what it means, we know how to 'go on' handshaking in the relevant cases_-'blindly', but non-accidentally correctly (as Wittgenstein might have said).

Suppose we have a feeling, a pleasure, for example, in eating smoked salmon on a Bath-Oliver biscuit with a little cream cheese, with lemon and pepper on top. We want to 'express' this pleasure, somehow. What notion of 'expression' might in question? Rosalind Hursthouse's paper “Arational Actions” (Hursthouse 1991) paper is very helpful for our purposes. (Robert Nozick also discusses this topic in Nozick 1993: 25-36.) We perform many 'expressive' actions, in the sense of symbolic actions. We hear about our pay cut and smash our coffee mug against the wall. We stand up when someone important enters the room. We throw up our hands in despair. We have funeral rituals. Many things we do are like this. Anthropology books are filled with these phenomena, unlike philosophy of action books and papers, to their detriment. (Does a 'rational planner' make such expressive gestures?) Now there is no reason why such rituals and expressive institutions cannot evolve in a way that is similar to the way that literal linguistic meanings evolve, by feedback mechanisms. This is the kind of meaningful 'expression' we need to think about—ritualized intentional activity_rather than the 
This is a pre-copyedited, author-produced version of an article accepted for publication in The Monist following peer review. The version of record Nick Zangwill, The Yummy and the Yucky: Expressive Language and the Agreeable, The Monist, Volume 101, Issue 3, July 2018, Pages 294-308 is available online at: https://doi.org/10.1093/monist/ony007.

unintentional 'expression' of embarrassment in blushing. This is how to think of the handshake and the other examples.

If this is true of ritualized non-linguistic meaningful behavior like the handshake, then language is bound to have the facility to have a similar expressive function. It would be odd if there were only non-verbal means of expressing attitudes, and only referential signaling was done in language. We can signal what we are thinking about, but we can also signal attitudes, both in conventional non-linguistic and linguistic ways. (Think of facial expressions.) Hence - why not an expressive predicate? Perhaps referential predication must already be in place, and, once it is in place, the sort of expressive predication we have imagined can hijack it. Consider the importance of showing dominance or submission in a social group. There is a need for words that express the relevant feelings that feature in hierarchical relationships. Thus, we may communicate attitudes without describing or even referring to them.

Steven Pinker nicely describes the way unambiguity is often inefficient in communicative interaction and ambiguity is more efficient and thus to be expected (Pinker 2007, Chapter 7). He describes and analyses various scenarios in which this is very plausibly the case. But for these scenarios to make sense, the ambiguity must serve to signal non-cognitive states, which means that we have a linguistic phenomenon (ambiguity) that has an expressive function. If so, an expressive predicate is also feasible. Not all non-referential language-games are expressive of non-cognitive mental states in this way, but some are.

Let us now build on this. Such expressive conventions mean that we can be insincere and deceptive - which is sometimes very important. It is often said, with the air of a platitude, that language is a means of communication, but as a generalization this is piously optimistic. We can use language to lie and conceal, and this is part of its point. It is not an extra bonus. The possibility of insincerity is important for both referential and expressive language.

Furthermore, and relatedly, since symbolic activity is intentional, we can distance ourselves from our symbolical actions, for many purposes. This means - and perhaps this is a central idea of Simon Blackburn's work on expressivism, which we will build on-we can reflect on attitudes; and we can discuss them with others (Blackburn 1984: 192, Blackburn 1998: 14). (An ironic Niezschean speculation would be that the possibility of moral thought depends on the ability to deceive!) 
This is a pre-copyedited, author-produced version of an article accepted for publication in The Monist following peer review. The version of record Nick Zangwill, The Yummy and the Yucky: Expressive Language and the Agreeable, The Monist, Volume 101, Issue 3, July 2018, Pages 294-308 is available online at: https://doi.org/10.1093/monist/ony007.

Expressive language thus would have a point. It would meet a need. This is crucial, since we want to know why we deploy these language forms, not merely that they are possible or even actual. But the point of such language-games need lie neither in reference to properties or objects in the world, nor in the possibility of correctness in attitude or judgement of the sort that we see in the language of beauty or morality. Expressive predication in the case of judgements of the agreeable raises different issues from those surrounding normative judgements where there an aspiration to correctness in judgement.

With a predicate, we can deliberate about yumminess and yuckiness. We can plan for yumminess. We can regret yuckiness. And so on. Without a predicate, such reflective thinking would be impossible. Furthermore, we need a predicate not just to reflect on our judgements, but also to agree or disagree with others. Suppose you say "X is delicious”. I can reply: "I agree with that”. With what? Well, that it is delicious. With a predicate, I can talk about what you like and about your liking. I can reply “That's true”, or "No I disagree”. But without a predicate, I can only repeat your “yummy” or say “yuck” instead. I can only imitate you or do the opposite. But I cannot agree with you or disagree with you. I am merely similar or different from you. With a predicate, all this changes. With a predicate, I can reply not only "yummy”, but "It is yummy", and you can then agree with my statement "It is yummy". And you can disagree saying "No it is too salty; it is yucky and not yummy". We can say that the food or drink is “yummy” and others can agree or disagree. We can discuss it. We can agree to differ. So expressive predication has an interpersonal point as well as a first-personal reflective point.

Thus we can see why a dedicated expressive language could evolve and how it would have a point. Or rather it evolves because it has a point. An expressive predicate would serve a need and because of that could come into existence in familiar evolutionary language-game-theoretic ways. Language-games that fulfill these needs would be encouraged and those that do worse at fulfilling these needs would be discouraged. Cultural evolution would thus throw up stable language-games that are expressive institutions surrounding the pleasures we take in eating and drinking.

\section{§5. The Frege-Geach Problem for the Agreeable}

The point about the point of expressive predication allows us to make progress in understanding some issues that a full account of expressive prediction should address. 
This is a pre-copyedited, author-produced version of an article accepted for publication in The Monist following peer review. The version of record Nick Zangwill, The Yummy and the Yucky: Expressive Language and the Agreeable, The Monist, Volume 101, Issue 3, July 2018, Pages 294-308 is available online at: https://doi.org/10.1093/monist/ony007.

Once we have practices of expressive predication, then issues of propositional structure arise. We can wonder about the meaning of "is delicious" in unasserted contexts, such as disjunctions, conditionals and propositional attitude contexts. The sentence " $\mathrm{X}$ is delicious" is not always used by a person who is taking pleasure in X. And yet the phrase must mean the same in and out of unasserted contexts if the usual logical entailments are to be preserved. For example: "Either $\mathrm{X}$ is delicious or $\mathrm{Y}$ is delicious": " $\mathrm{X}$ is not delicious"; so "Y is delicious". An account of this logical validity needs to be given. This is what is called the 'Frege-Geach problem', and it is often seen as a powerful objection to expressivism about moral thinking (Geach 1965).

It is not that we are tempted by realism about the agreeable as we are tempted by realism about morality and aesthetics_ goodness and beauty. There is no serious alternative to expressivism about the agreeable. Nevertheless, logical structure poses a puzzle for that account.

Before I make a?? suggestion, I want to note two points.

??Funniness is another case of the agreeable, but here I focus only on deliciousness in food and drink??

Firstly, the way the Frege-Geach problem arises for judgments of the agreeable is instructive. The problem arises for our thought and talk about the agreeable - the yummy or yucky —in a way that is different from the way it arises for morality and aesthetics. Once we have an expressive predicate and practices of expressive predicate for the agreeable, a Frege-Geach problem arises without a robust notion of correctness being in play. Furthermore, the fact that the Frege-Geach problem arises for the agreeable without notions of correctness in judgement casts light on what has to be done in areas, such as ethics or aesthetics on expressivist interpretations, where there are claims to correctness. Moral and aesthetic thought are subject to quite a robust conception of correctness in judgement. Two opposite judgements cannot both be right, or correct. One task for expressivism about morality or aesthetics, therefore, is to capture such normativity from the resources of expressivism. In those areas, the solution to the two problems - the normativity and Frege-Geach problems - will need to be integrated with each other. But such normativity is not in question for judgements of the agreeable, so expressivism about the agreeable is free of this integration problem.

Secondly, given expressive predication, we can say "If $\mathrm{x}$ is delicious then so is y" or "Either $\mathrm{x}$ or y is delicious". Or "Katy thinks that ice-cream is delicious". Once we have predication, we 
This is a pre-copyedited, author-produced version of an article accepted for publication in The Monist following peer review. The version of record Nick Zangwill, The Yummy and the Yucky: Expressive Language and the Agreeable, The Monist, Volume 101, Issue 3, July 2018, Pages 294-308 is available online at: https://doi.org/10.1093/monist/ony007.

can construct complex sentences, given the logical words that are available from the rest of language. But predicativity is not sufficient to solve the Frege-Geach problem for deliciousness, because it does not solve the identity of meaning problem; the problem is that "is delicious” means the same in and out of embedded contexts. Without that, the intuitive logical entailments fail. The availability of sentential form plus the availability of sentential connectives from the rest of our thought are necessary but not sufficient to solve the FregeGeach problem. For sentential logical form plus connectives do not explain how there is one meaning that can occur in and out of embedded contexts, which is necessary if the usual logical entailments are to hold.

$<<<<$ ??

I suggest that an account of why we need predication is the right place to look. In particular, reflection on, planning for, and discussion of, yumminess and yuckiness means thinking about types of attitudes, ones that we might or might not have at the time of reflection. When we do not have the attitude, what we think of, $w$

When we reflect, we may reflect on the kind of thought that we think of w When we do have the attitude. We do not need to actually have an attitude token to reflect on the type. Nevertheless, an attitude that we might reflect on without having it, is the same type of attitude that we might actually have and express in the relatively simple judgements " $\mathrm{X}$ is delicious".<<??>> Thus what we mean in the two cases is the same. This is the key to answering the Frege-Geach problem for the agreeable, or at least one major aspect of it—or so I suggest.

Reflective practical thought about the agreeable means thinking in terms of types not tokens.

That is, firstly, we can reflect not only on our actual token likings, but also of likings of a certain type, whether or not we actually have tokens of the type. And, secondly, we can discuss these abstract kinds of likings with others. And if we are planning for yumminess, we may not have a token of the liking yet; that is the point of the planning! From this we can see that this is 
This is a pre-copyedited, author-produced version of an article accepted for publication in The Monist following peer review. The version of record Nick Zangwill, The Yummy and the Yucky: Expressive Language and the Agreeable, The Monist, Volume 101, Issue 3, July 2018, Pages 294-308 is available online at: https://doi.org/10.1093/monist/ony007.

why it is useful to have a predicate But once we have a predicate, we have sentential form. But then given the logical constants we have the possibility of complex sentences in which embedded elements are not asserted. (Not just 'and'!) Given that it is types of attitudes that are in question, it is those types that figure both in and out of complex contexts. This explains the identities of meaning that we need.

Note again that we do not need a robust conception of correctness to achieve this, although robust normativity also needs to be explained where it exists. The point of the propositional structure might be different in cases where there are no normative aspirations, from cases where there are such aspirations. This is something that moral and aesthetic expressivists should take on board.

The important thing, then, is the point of propositional structure for expressive language-games which involve types not tokens of attitudes. Given that point, what we might call 'the point point', we then have an account of the identities of meanings in and out of embedded contexts, which is necessary for explaining logically valid inferences.

$<<$ PA contexts??>>

If apple crumble is delicious, then so is apple strudel.

Apple crumble is delicious.

So apple strudel is delicious.

Pleasure in eating apple strudel can be concretely realized in various token particular pleasures. But it is also a type that could be simultaneously instantiated in London and Sao Paulo. ???>>

\section{§6. Rules and Meaning}

The, or one, basic form that the Frege-Geach problem takes is that " $\mathrm{X}$ is delicious" is supposed to be said by someone who has pleasure in $\mathrm{X}$; but someone who uses " $\mathrm{X}$ is delicious" in an embedded context need not be having pleasure in X. So some other account must be given of 
This is a pre-copyedited, author-produced version of an article accepted for publication in The Monist following peer review. The version of record Nick Zangwill, The Yummy and the Yucky: Expressive Language and the Agreeable, The Monist, Volume 101, Issue 3, July 2018, Pages 294-308 is available online at: https://doi.org/10.1093/monist/ony007.

the meaning of "is delicious" in embedded contexts than its being used when the speaker has pleasure in $\mathrm{X}$.

Let us look more closely at the rule of assertion for judgements of the agreeable. One thought is that it is a conditional

[If one has a feeling of pleasure of a certain type, in the right circumstances, on tasting $\mathrm{x}$, then one must/may assert a judgement of the agreeable, that $\mathrm{x}$ is yummy.]

Notice also that the judgement has no subjective content "I have such and such a feeling”, but its rule of assertion is subjective. In other words, it is a reflective judgement. Non-subjective expressive judgements have essential origins in a subjective rule.

Someone might object that this account generates Wittgensteinian worries about 'privacy', since the person in question needs to reidentify phenomenologically similar attitudes on the basis of introspection, with no help from knowledge of behavior. I think that there are no problems here: we can do that. Furthermore, the interpretation of Wittgenstein is defective; see Zangwill 2017.)

However, the rule seems to generate a Frege-Geach problem since while that rule might seem alright for simplex non-embedded assertions, it gives us no guidance for what the rule of assertion is for complex sentences involving " $\mathrm{X}$ is yummy” as a constituent.

Notice, however, that this rule for the assertion of the simple non-embedded judgement of the agreeable is a conditional, with an imperative or deontic proposition as a consequent and an antecedent with a subjective component.

One response to the Frege-Geach problem, at this point, would be that we need a different rule for different complex constructions corresponding to the type of embedding in question. How would it look if we tried to formulate a rule of assertion for a conditional with an agreeable antecedent? Perhaps:

[If were to have at attitude of a certain kind, in the right circumstances, then then we should have another judgement, perhaps have a belief or make another expressive jugement].

There would be a shared subjective element of both rules for the categorial non-embedded assertion and the conditional. But should the idea be that the content of the conditional is given in part by the conditional rule just sugested? This is tempting but I think this should be resisted. 
This is a pre-copyedited, author-produced version of an article accepted for publication in The Monist following peer review. The version of record Nick Zangwill, The Yummy and the Yucky: Expressive Language and the Agreeable, The Monist, Volume 101, Issue 3, July 2018, Pages 294-308 is available online at: https://doi.org/10.1093/monist/ony007.

My strategy is to look sideways at the referential case, which will then help us to get it right about the expressive case, and avoid a Frege-Geach problem.

What is the rule of assertion for " $\mathrm{X}$ is square”? It might be something like

[If you have an experience as of $\mathrm{X}$ being square, in the right circumstances, then go ahead and believe that $\mathrm{X}$ is square].

What is of fundamental importance is that this rule does not give the content of the judgement that something is square. Perhaps if you grasp the meaning of " $\mathrm{X}$ is square" then you grasp the assertion rule. The meaning explains the verification; but they are not the same.

This has much to teach us about the expressivist assertion rule. We should say the same as what we should say about rules for referential language. Expressivist rules do not give the meaning of expressivist judgements. This was part of the point of my introducing expressivist language by means of evolutionary language-game-theory. If we distinguish rules and meaning, then, in one fell swoop, that cuts out the main source for the Frege-Geach worry. In the non-embedded categorial case, the rule says you can assert " $\mathrm{X}$ is yummy” when $\mathrm{X}$ tastes good to you (other things being equal). There is supposed to be a puzzle generated by accounting for what " $\mathrm{X}$ is yummy” means in the complex case of an embedded occurrence of that sentence. But that dialectic makes an assumption which we should reject, which is that the rule is the meaning. (This was the error of Logical Positivism.) In a categorial, non-complex referential case, what we mean when call something square is not given by the assertion rule [assert it when you have the relevant experience]. Similarly, what you mean when you call something yummy, in a categorial, non-complex case, is not given by the assertion rule. If so, there is no Frege-Geach worry about our assertion of embedded sentences without the presence of the pleasures that are part of the assertion rule in the simple case. That mistakes rule and content, meaning and verification. What we mean in the "is square" case is given by reference; and we know that in operating with the assertion rule. That reference function is the same in simple and in embedded contexts. Similarly, what we mean in the "is yummy" case is given by expression. And that expression function is also the same in simple and in embedded contexts.

This is also why the language-game-theoretic way in which I set expressivist language is important. The expressive meaning function arises as it does, as an institution whereby linguistic acts have an expressive function. That is what generates the being and identity of the expressive proposition. It is not how the speaker happens to feel when asserting " $\mathrm{X}$ is yummy”. 
This is a pre-copyedited, author-produced version of an article accepted for publication in The Monist following peer review. The version of record Nick Zangwill, The Yummy and the Yucky: Expressive Language and the Agreeable, The Monist, Volume 101, Issue 3, July 2018, Pages 294-308 is available online at: https://doi.org/10.1093/monist/ony007.

There is an important point about sincerity here. Suppose I utter " $\mathrm{X}$ is yummy” ironically. Then I have said what I have said, whatever feelings and pleasures I may or may not have. The point applies equally to non-linguistic expressive gestures with institutionalized meanings. If I stand up or take my hat off when someone important comes into a room, then I have expressed respect, whatever I am thinking. I may inwardly be seething with contempt. Still, I have expressed respect since that is what that gesture means. This is crucial for the Frege-Geach problem.

Expressivist theories should never have said that occurrences of " $\mathrm{X}$ is yummy" somehow derive from pleasures had at X. That is too unstructured and casual a framework. Instead, I have suggested that there is a complex institution in which " $\mathrm{X}$ is yummy" sentences have a certain function. Expression means something like this or else it means nothing useful. (The model of blushing expressing embarrassment will not serve, for example.)

It is the same with referential language. The person who knowingly utters the word "dog" or "blue" on stage, or ironically, still refers to dogs or blueness. It is a ritualized institution and once it exists one cannot, like Humpty Dumpty, try to make what one says mean something different, by some interior mental act. Similarly, again following Davidson, I do not mean anything different just because one is using words metaphorically.

In these remarks, I do not take myself to have provided a full compositional semantics for the agreeable. But I do take myself to have removed one of the major reasons for thinking that it cannot be given. That reason given, when posing the Frege-Geach problem, presupposes the collapse of the meaning and assertion conditions of expressive sentences.

$<<$ ??CUTThe function of referential language... is it to convey to the receiver what the sender is thinking of, or associates with certain public tokens? No. No the function is just to refer to what referent. Similarly, in expressive language... is the function to convey to the receiver what feelings to the sender is thinking of, or associates with certain public tokens? No.

So expressive language is not really about communicating feelings from sender to receiver or about outer linguistic displays of inner feeling. Compare an actor on a stage uttering referential and expressive language. Whatever is going on in them, whatever beliefs and feelings they have, they nevertheless refer and they express in accordance with the ritualized institutions that constitute linguistic reference and expression. ??CUT>> 
This is a pre-copyedited, author-produced version of an article accepted for publication in The Monist following peer review. The version of record Nick Zangwill, The Yummy and the Yucky: Expressive Language and the Agreeable, The Monist, Volume 101, Issue 3, July 2018, Pages 294-308 is available online at: https://doi.org/10.1093/monist/ony007.

\section{§7. Consistency and Inconsistency}

It might be objected: what about consistency and inconsistency? This appears to be another problem for the evolutionary language-game theoretic account of expressive language. We surely disagree with each other when we say "It's yummy" and another says "It's yucky" or "It is not yummy". And we disagree because what one says is inconsistent with what the other says.

Thus far, we have achieved predication and sentential form; but that does not suffice to understand the mental acts that deploy such predication in judgements of the agreeable. To judge, even about the agreeable, is to exclude the opposite judgement. To judge that $\mathrm{x}$ is $\mathrm{F}$ is tacitly to judge that it is not the case that $\mathrm{x}$ is not-F. I take a judgement to be an act of predication. A question is: in what way does a judgement of the agreeable exclude the opposite judgement? And: how can it exclude the opposite judgement?

One idea would be that this arises from the fact that the attitudes expressed in these judgements are inconsistent, in the sense that they are metaphysically incompatible. A person can have both attitudes; but something's being one attitude metaphysically excludes that thing also being the opposite attitude. But then how do we get an inconsistency between judgements that is more than that?

$<<<$ ??

Do we need a notion of logical consistency in order to have an identity of content in and out of embedded contexts that we need for the Grege-Geach problem? Without content identity, intuitively valid logical inferences will be rendered invalid due to equivocation. But, it can be argued, negation is an embedded context. So we need content identity to make sense of the inconsistency between judgements with the content $\mathrm{p}$ and those with the content not-p.

Contents of judgements are important and an essential part of the Frege-Geach problem. But it is not all of it. A proper notion of consistency and inconsistency $<<$ ? ? >> is also essential. It is true that " $\mathrm{x}$ is Yummy" implies " $\mathrm{x}$ is not yucky". But how is the judgement " $\mathrm{x}$ is yummy" inconsistent with the judgement " $\mathrm{x}$ is not yummy"? (Derek Baker and ??? Woods pursue this issue in the case of moral expressivism; see Baker and Woods20???.)?? 
This is a pre-copyedited, author-produced version of an article accepted for publication in The Monist following peer review. The version of record Nick Zangwill, The Yummy and the Yucky: Expressive Language and the Agreeable, The Monist, Volume 101, Issue 3, July 2018, Pages 294-308 is available online at: https://doi.org/10.1093/monist/ony007.

Once we have achieved predication, there is $a$ sense in which there is consistency and inconsistency between the judgements, which is not merely that the liking expressed by "yummy” is metaphysically incompatible with the disliking expressed by “yucky”. We need consistency and inconsistency in what is judged, not in the judgements or in the feelings from which the judgements arise. The judgements expressed in “ $x$ is yummy” and “ $x$ is yucky” are inconsistent in that the predications are inconsistent, just as the judgements expressed in " $\mathrm{x}$ is yummy” and " $x$ is not yummy” are inconsistent because the predications are inconsistent. This transcends attitude inconsistency.

It would be implausible to argue that in order to account for inconsistency, we need full-blown realism about the yummy and the yucky. Equally, it would be implausible to argue that in order to account for inconsistency, we need the possibility of correctness and incorrectness in judgements of the yummy and the yucky. There must be some other way of handling inconsistency, which is, of course, relatively good news for moral and aesthetic expressivists. $<<$ ??Here we have a version of the negation problem, which many think is at the heart of the Frege-Geach problem (Unwin 1999). <<??>>

We need a notion of judgement inconsistency that goes beyond attitude inconsistency and inconsistency but which does not require normative aspiration in judgement. My suggestion is the following. In the sense of "inconsistent" that we want: hope is inconsistent with belief that what is hoped for is impossible, and fearing $\mathrm{X}$ is inconsistent with not believing that $\mathrm{X}$ is dangerous. This is rational inconsistency. And the thought is that " $\mathrm{X}$ is yummy" and " $\mathrm{X}$ is yucky" are rationally inconsistent in this sense. Judging that $\mathrm{x}$ is yummy makes it irrational also to judge that $\mathrm{x}$ is yucky and also $\mathrm{x}$ is not yummy. Crucially, this kind of incompatibility between judgements is not possible because there is some idea of correctness and incorrectness in judgements of yumminess and yuckiness. The sense of consistency in question is unlike that in morality and aesthetics, where each of the opposite judgements in question has the ambition to be correct but only one of the two judgements, or rather at most one of the two, can achieve that ambition. The consistency and inconsistency that we want for the agreeable is judgement inconsistency. This is internal to predication; it goes beyond attitude consistency and 
This is a pre-copyedited, author-produced version of an article accepted for publication in The Monist following peer review. The version of record Nick Zangwill, The Yummy and the Yucky: Expressive Language and the Agreeable, The Monist, Volume 101, Issue 3, July 2018, Pages 294-308 is available online at: https://doi.org/10.1093/monist/ony007.

inconsistency, but does not depend on the judgements not both being able to achieve the goal of correctness. This is the middle path that we need to take. And the idea is that rationality gives us that. We can thus have a notion of consistency and inconsistency beyond attitude inconsistency, yet without normative ambition in judgement.

Some would build on such an account of inconsistency to make for an understanding of negation for expressivism (Unwin 1999). I make no commitment to this, except to say that I am not unsympathetic. What I have said does not suffice, however. Still, consistency and inconsistency need to be explained whether or not we can use them to explain other puzzling phenomena.

$<<$ CUT??? Perhaps we need to understand judgement consistency if we are to understand correctness, where we have correctness. Some accounts of negation in contents deploy notions of consistency and inconsistency in judgement. CUT

It seems that we need an idea of consistency and inconsistency insofar as we have can aspirations to correctness. For correct judgements exclude their opposites from being correct or true. But judgement inconsistency, explained in terms of rationality, is a basic idea that helps explains other things.

\section{§8. Coda}

I have explored a way of understanding expressive language for talking about a crucial aspect of our experience of food and drink, which situates itself in, or not far from, the evolutionary language-game-theoretic framework that we have for understanding referential language. Much more work needs to be done to develop the account in empirical and mathematical detail. Such an account, I believe, would have explanatory power and is revealing of actual expressive language-games. Furthermore, that account is in a good position to explain the complexity of expressive language once we are careful about what expression comes to, and notions of consistency and inconsistency in judgements of the agreeable can be explained. Judgements of the yummy and the yucky may not aspire to be like judgements of goodness, truth and beauty, but what they do is sophisticated, interesting and important in their own way. 
This is a pre-copyedited, author-produced version of an article accepted for publication in The Monist following peer review. The version of record Nick Zangwill, The Yummy and the Yucky: Expressive Language and the Agreeable, The Monist, Volume 101, Issue 3, July 2018, Pages 294-308 is available online at: https://doi.org/10.1093/monist/ony007.

*For helpful comments, many thanks to Jack Woods and a referee for the journal. I would also like to thank my daughter, Kate (nearly three years old) for the benefit of her extensive expertise on the subject of the yummy and yucky. 
This is a pre-copyedited, author-produced version of an article accepted for publication in The Monist following peer review. The version of record Nick Zangwill, The Yummy and the Yucky: Expressive Language and the Agreeable, The Monist, Volume 101, Issue 3, July 2018, Pages 294-308 is available online at: https://doi.org/10.1093/monist/ony007.

\section{$\underline{\text { References }}$}

Robert Aumann and Adam Brandenburger 1995: "Epistemic Conditions for Nash Equilibrium", Econometrica 63: 1161-1180. 20

Ken Binmore 2009: “Do Conventions Need to Be Common Knowledge?”, Topoi 27: 17-27

Simon Blackburn 1984: Spreading the Word, Oxford: Oxford University Press.

Simon Blackburn 1998: Ruling Passions, Oxford: Oxford University Press.

William Capra 2014: “Artifact Liberation”, Philosophy Now 104 ???

Donald Davidson 1978: “What Metaphors Mean”, Critical Inquiry, 5: 31-47.

Mauro Englemann 2011: “Wittgenstein’s ‘Most Fruitful Idea’ and Sraffa”, Philosophical Investigations 26: 155-178.

Mauro Englemann 2013: Wittgenstein’s Philosophical Development, Palgrave Macmillan.

Paul Grice 1957: “Meaning”, Philosophical Review 66: 377-388.

Rosalind Hursthouse 1991: “Arational Actions”, The Journal of Philosophy 88: 57-68

Immanuel Kant 1928: Critique of Judgement, Oxford: Oxford University Press.

Leon Kass 1994: The Hungry Soul, New York: Free Press.

Carolyn Korsmeyer 2002: Making Sense of Taste, Ithaca: Cornell University Press.

John Maynard-Smith 1982: Evolution and Theory of Games, Cambridge: Cambridge University Press.

Tim Lewens 2013: “Cultural Evolution”, Stanford Encyclopedia of Philosophy.

David Lewis 1969: Convention, Oxford: Blackwell.

John MacFarlane 2014: Assessment Sensitivity: Relative Truth and Its Applications, Oxford: Oxford University Press.

Ruth Millikan 2005: Language: A Biological Model, Oxford: Oxford University Press. Martin Nowak and David Krakauer 1999: “The Evolution of Language”, Proceedings of the National Academy of Sciences of the United States of America, Vol. 96, No. 14: 8028-8033. 
This is a pre-copyedited, author-produced version of an article accepted for publication in The Monist following peer review. The version of record Nick Zangwill, The Yummy and the Yucky: Expressive Language and the Agreeable, The Monist, Volume 101, Issue 3, July 2018, Pages 294-308 is available online at: https://doi.org/10.1093/monist/ony007.

Martin Nowak, Joshua Plotkin, and David Krakauer 1999: “The Evolutionary Languagegame”, Journal of Theoretical Biology 200, 147-162.

Robert Nozick 1993: The Nature of Rationality, Princeton, NJ: Princeton University Press. Stephen Pinker 2007: The Stuff of Thought, Harmonsworth: Penguin.

Brian Skyrms 2010: Signals, Oxford: Oxford University Press.

Charles Stevenson 1937: “The Emotive Meaning of Ethical Terms”, Mind, 46: 14-31.

Timothy Sundall 2011: “Disagreement about Taste”, Philosophical Studies. ???

Isidora Stojanovic 2007: “Talking About Taste: Disagreement, Implicit Arguments, and Relative Truth”, Linguistics and Philosophy 30: 691-706.

Nicholas Unwin 1999: “Quasi-Realism, Negation and the Frege-Geach Problem”, Philosophical Quarterly 49, 337-52.

Ludwig Wittgenstein 1953: Philosophical Investigations, Oxford: Blackwell.

Nick Zangwill 2014: “Metaphor as Appropriation”, Philosophy and Literature 38: 142-152.

Nick Zangwill 2017: “Rules and Privacy: Remarks on Philosophical Investigations, 202”, in Proceedings of the 38. International Ludwig Wittgenstein Symposium, Kirchberg am Wechsel, Austria, Publications of the Austrian Ludwig Wittgenstein Society.

Nick Zangwill 2018: "Beauty and the Agreeable: A Critique of Experimental Aesthetics”, in Florian Cova and Sébastien Réhault (eds.), Advances in Experimental Philosophy of Art, London: Bloomsbury. 